\section{"Bienvenidos al cambio": la construcción de la imagen política de Sebastián Piñera (2009) y Pedro Pablo Kuczynski (2016)}

Marina Mendoza ${ }^{(1)}$

Resumen: La creciente inserción de empresarios en las más altas esferas gubernamentales de los países latinoamericanos ha despertado un renovado interés por analizar y comprender las modalidades de construcción de liderazgos políticos, sus herramientas y estrategias.

Este artículo propone analizar comparativamente el proceso de construcción de la imagen política de dos exponentes del ámbito privado-empresarial, el ex mandatario peruano Pedro Pablo Kuczynski (2016-2018) y el actual presidente chileno, Sebastián Piñera (2010-2014/2018-). Se pretende sistematizar este proceso, puntualizando en la combinación de herramientas y tácticas de comunicación, imagen y marketing político utilizadas para posicionarlos en la esfera pública como representantes de una "nueva política".

Palabras clave: imagen política - liderazgo - empresarios - nueva derecha - cambio - Perú - Chile.

[Resúmenes en inglés y portugués en la página 256]

(1) Becaria Doctoral del CONICET, Doctoranda en Ciencias Sociales (FSOC-UBA), con sede en el Instituto de Estudios de América Latina y el Caribe (IEALC). Licenciada en Sociología (FSOC-UBA, 2015) y Licenciada en Relaciones Públicas (UP, 2009). Ha cursado estudios de posgrado en Derechos Humanos y Genocidios (Fundación Luisa Hairabedian/UMSA), Memoria colectiva y prácticas de resistencia (CLACSO), Integración regional y regionalismo en Europa y América Latina (Escuela Complutense Latinoamericana), Geopolítica y Defensa Latinoamericana (CCC Floreal Gorrini) y Comunicación Política (Centro de Comunicación La Crujía). Es Jefa de Trabajos Prácticos de la cátedra Sociología Política de América Latina (UBA), en la carrera de Sociología (FSOC-UBA). Forma parte del Ubacyt "Estado, élites y grupos económicos en América Latina”, el PICT "Estado, élites y políticas públicas en América Latina 2000-2018” y el GT-CLACSO "Élites empresariales, Estado y dominación”, dirigidos por la Dra. Inés Nercesian. 


\section{Introducción}

En un contexto de ascenso de figuras del ámbito empresarial a las altas esferas gubernamentales con una estrategia de posicionamiento que prioriza la eficiencia en la gestión y el expertise del ámbito privado, emerge el interés por explorar las formas de comunicación que desarrollan en contextos de campaña y espacios de gobierno.

El discurso de alejamiento del ámbito político y la pertenencia al mundo empresarial como una variable de discriminación positiva han reconfigurado las estrategias y mecanismos de construcción de liderazgos. Como resultado de este proceso, la opción por el posicionamiento en el eje del cambio pro futuro, presentándose como exponentes de una forma innovadora de hacer política, que en ocasiones adquiere un carácter refundacional, es empleada con frecuencia por estos candidatos empresarios. Si bien esta estrategia no es exclusiva del actual momento histórico, resulta funcional a la necesidad de justificar la inserción de la dirigencia empresarial a la gestión pública.

La política y su automática asimilación con la corrupción, aparece, en este escenario, como el mal que es preciso superar. Sus lógicas, como sostendrán estos exponentes en sus discursos, se han mostrado obsoletas para viabilizar la nueva etapa que requiere tecnocracia y el know how del ámbito empresarial. Esto explica, en buena medida, la conformación de sus equipos ministeriales con hombres y mujeres con una fuerte impronta corporativa, que interpretan la regulación estatal como un desvío propio de los "populismos latinoamericanos".

Los casos de Pedro Pablo Kuczynski (2016-2018) y Sebastián Piñera (2010-2014/2018) que se compararán en este artículo, ofrecen claves explicativas de los procesos antes señalados. Ambos construyeron su imagen política a partir de cuatro mecanismos: a. la ponderación de su gestión en el ámbito privado como una demostración a priori de su capacidad de gestionar el ámbito público; b. la eficiencia como un medio para sanear el mal funcionamiento del Estado; c. la construcción de una ética de vocación pública y sacrificio; d. su capacidad de canalizar el cambio que sus sociedades exigían, frente al fracaso de la política.

Para sistematizar la comparación, se analizarán las campañas políticas de ambos candidatos, en un período signado por las legislaciones y los cronogramas electorales locales. Para el caso peruano, se toma el período diciembre 2015-junio 2016: la primera vuelta, realizada el 10 de abril, no arrojó un ganador, en tanto ninguno de los candidatos logró obtener el $50 \%$ de los votos. La segunda vuelta, desarrollada el 5 de junio entre la hija del exmandatario, Keiko Fujimori y PPK, le dio la victoria definitiva al candidato del neoliberalismo corporativista. En un contexto de fuerte polarización entre la derecha dictatorial y la derecha neoliberal, la segunda opción resultó victoriosa.

Para el caso chileno, se tomará la campaña de 2009-2010 que le otorgó la victoria para su primer mandato (2010-2014), en tanto su segunda administración (2018-) persigue lógicas de posicionamiento y comunicación atravesadas por el aprendizaje político que obtuviera de su primera experiencia. En efecto, la procedencia no sólo personal del presidente, sino también de una parte mayoritaria de su gabinete, de las más altas jerarquías empresarias, obligó a introducir profundas modificaciones en su composición ministerial y sus formas de resolución de problemáticas, a los pocos meses de asumir. Este dato 
no es menor, si se consideran los conflictos de interés originados en la colusión públicoprivada, lo que en este caso se manifestó incluso en modificaciones legislativas. En las elecciones presidenciales chilenas también hubo una segunda vuelta el 17 de enero de 2010, en tanto en la primera vuelta, realizada el 13 de diciembre de 2009, ningún candidato alcanzó más de la mitad de los votos. El período de análisis para el caso chileno, será, entonces, noviembre 2009-enero 2010, contemplando ambas etapas.

En ambos casos, se trabajará con tres elementos de las campañas: 1. Programas de gobierno; 2. Debates presidenciales; y 3. spots televisivos. El análisis combinado de estos elementos permitirá identificar los temas de campaña, los ejes y el posicionamiento estratégico de los candidatos en el escenario electoral. La comparación de estos dos casos resultará útil a los fines de caracterizar estas formas de construcción de liderazgos políticos de empresarios a presidentes.

\section{Entre la renovación, el know how, la eficiencia y la vocación de servicio}

La década de 1990 representó para América Latina un período de profundas transformaciones. Las reformas estructurales de los Estados, la instauración del neoliberalismo y el desgaste de las formas históricas de representación política que significaron el agotamiento de la "matriz nacional-popular estatista" y su reemplazo por un modelo de libre mercado (Garretón et al, 2003), contribuyeron a la aparición de formatos novedosos de ejercicio del poder. Este proceso se dio en simultáneo con la recuperación de las democracias latinoamericanas acaecida entre las décadas de 1980 y 1990, lo que ofreció un impulso remozado a la apertura de nuevos canales de comunicación entre la ciudadanía y los representantes políticos -debates televisados, sondeos de opinión, estrategias en medios masivos (Landi, 1991)-.

En Perú, entre 1989 y 1992 se produjo el colapso del sistema de partidos y una profunda crisis de representación, lo que provocó la gradual pérdida de apoyo ciudadano de los partidos tradicionales y, en algunos casos, su desaparición de la esfera política. La victoria de Alberto Fujimori en 1990 a partir de la construcción de su imagen pública como outsider de la política, se explica en un contexto de vacío de representación, radicalización de la violencia política, altos índices inflacionarios y una fuerte recesión (Tanaka, 2002). Aquí "el colapso del sistema de partidos dio lugar a la aparición de regímenes autoritario-competitivos, es decir, gobiernos legítimos desde el punto de vista electoral, pero que no respetan mecanismos básicos de accountability horizontal propios de toda democracia; su legitimación descansa sobre la apelación a principios plebiscitarios" (Tanaka, 2006). En efecto, durante los diez años de gobierno fujimorista, Perú asistió a un proceso de repliegue democrático que se hizo manifiesto a partir del autogolpe de 1992 y que permite caracterizar este gobierno como una dictadura ${ }^{1}$.

Tras el retorno a la democracia en el año 2000 -posibilitada por la renuncia de Alberto Fujimori ${ }^{2}$-, se conformó un gobierno de transición presidido por Valentín Paniagua, quien ejerció la presidencia entre noviembre del 2000 y julio de 2001. A partir de entonces, se sucedieron tres administraciones (Alejandro Toledo, 2001-2006; Alan García, 
2006-2011; Ollanta Humala, 2011-2016) que mantuvieron y profundizaron el modelo económico impuesto por Fujimori.

La victoria de Pedro Pablo Kuczynski en las elecciones de 2016 significó el triunfo del candidato del establishment económico. El ex Ministro de Economía de Alejandro Toledo (2001-2006) y Ministro de Energía y Minas en el gobierno de Fernando Belaúnde Terry (1980-1985), irrumpió como una opción viable de la centroderecha liberal al canalizar el rechazo que generó la candidatura de Keiko Fujimori, hija del ex mandatario procesado por violaciones a los derechos humanos. En un contexto de polarización entre las fuerzas de la derecha neoliberal y la derecha dictatorial, predominó la opción por la primera.

Su candidatura se viabilizó mediante el armado de una estructura partidaria creada en octubre de 2014 que amalgamó su nombre con el del partido, Peruanos por el Kambio. A pesar de su experiencia en la gestión pública, se presentó como un candidato con amplia formación técnica en el ámbito privado y en organismos internacionales, destacando su trayectoria en el Banco Mundial y en el Fondo Monetario Internacional. Integró los directorios de bancos y entidades financieras y otras ligadas a la industria minera. La campaña electoral fue un fiel reflejo de la volatilidad electoral, la debilidad institucional y la fragmentación de partidos que caracteriza el sistema peruano: para la primera vuelta electoral que se celebraría el 10 de abril de 2016, se inscribieron diecinueve partidos y agrupaciones. En Chile, tras el triunfo del "No" en el plebiscito de 1988 y el fin de la dictadura pinochetista (1973-1989), se abrió un proceso de democratización que incluso en el presente -y con mayor ahínco-, se presenta incompleto debido a la persistencia de "enclaves autoritarios" (Garretón y Garretón, 2010) que restringen los márgenes de acción de las instituciones y actores políticos. Al igual que en Perú, el neoliberalismo se impuso en Chile por la vía autoritaria, siendo ambos casos considerados como modelos "exitosos" de libre mercado. Desde el retorno de la democracia hasta la elección de 2009 se sucedieron cuatro gobiernos de la Concertación de Partidos por la Democracia que convivieron con una minoría opositora de derecha que implementó una política de consensos para acumular fuerzas (Fazio Rigazzi, 2011). Si bien el sistema de partidos que surge tras diecisiete años de gobierno militar presenta cambios respecto al de 1973, también muestra signos de continuidad, como la política de los consensos que caracteriza a la democracia chilena desde su transición.

La victoria de Piñera se dio en el marco de un doble proceso de desgaste de la Concertación, con un candidato que no logró canalizar los votos de la centroizquierda y un fenómeno regional de incipiente repliegue de los gobiernos posneoliberales (Sader, 2009) que continuaría en 2015 con el triunfo de Mauricio Macri en Argentina. Con el 51.6\% de los votos totales, la derecha regresaba al poder por vías democráticas por primera vez desde 1958, de la mano de un "típico representante de la derecha chilena": profesional, millonario y católico conservador (Durand, 2010). Su vasta trayectoria empresarial como dueño y accionista en bancos e instituciones financieras (Citicorp, Bancard-, medios de comunicación -Chilevisión-, transporte aéreo -LAN-, clubes de fútbol-Colo-Colo) e instituciones de salud (Clínica Las Condes), le valió la calificación de Forbes como uno de los quince millonarios más poderosos del mundo en 2011 (ya en ejercicio del cargo presidencial y habiéndose desprendido de las acciones de LAN y Chilevisión para evitar conflictos de interés). 
La elección de Piñera significó el triunfo del gran empresariado y, especialmente, de uno de los “dueños del país" (Fazio Rigazzi, 2011). Coalición por el Cambio fue la estructura partidaria que impulsó su candidatura, una alianza de dos partidos de derecha tradicionales (ex Alianza por Chile): la Unión Demócrata Independiente (UDI) y Renovación Nacional (RN).

Contrario al carácter improvisado que se les adjudicó a los gobiernos empresarios, basado en el aparente desconocimiento de la gestión pública, el Programa de gobierno para el cambio, el futuro y la esperanza que lo llevó a la presidencia, fue el resultado de dos años de trabajo de un equipo de 1200 profesionales, empresarios y tecnócratas denominado Grupo Tantauco.

Tanto el gobierno de PPK como el de Piñera pueden inscribirse en lo que Francisco Durand (2010) denominó "activismo empresarial democrático", es decir, una forma de participación política del empresariado mediante la cual, en lugar de ocupar el poder por medios violentos -golpes de Estado, invasiones militares, revueltas empresariales-, lo hacen respetando las reglas democráticas. En estos casos, se trata de un tipo de acción política empresarial que califica como "candidatos empresarios en partidos conservadores", esto es, una forma de activismo cuya importancia radica en ser renovador. Esta modalidad se manifiesta en la participación de empresarios "sea en nuevos o viejos partidos, ganadores o no, que se reivindican como portadores de la renovación política, el cambio económico en dirección al mercado y que, además, buscan el realineamiento internacional con EEUU" (Durand, 2010).

Sin entrar en la discusión respecto a si estos gobiernos pueden inscribirse o no dentro de la tipología de "nueva derecha", destacan al menos dos rasgos de su construcción discursiva que reflejan el carácter novedoso de estas expresiones políticas. La primera es la apelación al cambio como pilar de sus candidaturas: como sostiene Ansaldi (2017), "históricamente, la posición política de derecha estuvo asociada a la resistencia al cambio, es decir, al conservadurismo", mientras que una buena parte de las propuestas políticas recientes "han hecho de la palabra cambio el núcleo duro de sus propuestas" (p. 34), si bien el cambio puede significar, también, el retorno a un pasado considerado mejor.

La segunda se desprende de la clásica concepción del Estado como poco eficiente o mal administrado, diagnóstico al que se añade automáticamente la necesidad de intervención de los empresarios capitalistas para gestionar eficazmente el aparato estatal (Ansaldi, 2017, p. 40). Una nueva etapa histórica en la que se asume superado el conflicto de clase, exige gobernantes expertos, que sean capaces de trasladar el know how de la gestión privada al mundo público. Con un dato particular: la creciente presencia de CEOs y gerentes de grandes empresas.

Coincidimos con el autor en que, más que nuevas derechas, las candidaturas de PPK y Piñera evidenciaron elementos novedosos de una vieja derecha: la apelación al cambio, el uso de un discurso desideologizado y, podemos agregar, la interpelación a los sectores populares y la exaltación de un ethos de sacrificio personal en pos del beneficio colectivo. También encontramos que, como sostiene Giordano, estas nuevas expresiones de derecha se diferencian de sus antecesoras en su defensa de la democracia representativa (2014, p. 50). 
Ambos candidatos construyeron su imagen a partir de un discurso basado en tres vectores: el cambio y la necesidad de renovación de la política; el sacrificio y la gesta patriótica que significaría para estos exitosos hombres y mujeres del mundo privado desempeñar un cargo público; y el uso del know how adquirido en el ámbito corporativo como un medio para gobernar eficientemente.

En línea con lo que sostiene Bourdieu (1999), en este artículo se entiende a los discursos en su carácter performativo, es decir, no como meros actos de enunciación, sino como prácticas que generan transformaciones en la realidad social, permeadas por el lugar que ocupa el enunciador y el enunciado, así como el contexto histórico en el que circulan los mensajes. En los dos casos que se analizan en este trabajo, se observa el agotamiento de las formas tradicionales de representación, la instauración de un discurso de ineficiencia de los mecanismos de gestión estatal empleados hasta el momento y, particularmente en el caso peruano, el miedo frente a la posibilidad del retorno autoritario. Las privatizaciones de la década previa, el "nuevo discurso de éxito económico y de nuevas oportunidades" (Durand, 2010), así como la creciente concentración del poder económico, delinearon un escenario favorable para el ascenso de los empresarios a la gestión pública. Estos empresarios supieron explotar eficazmente su experiencia en el ámbito privado como una demostración de su capacidad para gestionar el Estado, construyendo una imagen de heroísmo y vocación pública y apelando a la necesidad de edificar una nueva forma de gobernar, encabezada por tecnócratas y expertos.

\section{Candidatos a debate ${ }^{3}$ : la canalización del discurso del cambio}

Para la definición de las elecciones presidenciales chilenas de 2009 se organizaron cinco debates televisivos y uno radial. En esta oportunidad, se analizan dos debates televisivos que se realizaron para la primera y segunda vuelta, transmitidos por el canal estatal Televisión Nacional de Chile (TVN) y la Asociación de Televisión Nacional de Chile (Anatel), respectivamente .

El primero se desarrolló bajo el nombre Decisión '09 en los estudios de TVN el 23 de septiembre de 2009 y contó con la participación de cuatro postulantes: Marco EnríquezOminami Gumucio, candidato de Nueva Mayoría para Chile, una alianza conformada en 2009 entre el Partido Ecologista, el Partido Humanista y movimientos políticos independientes; Eduardo Frei Ruiz Tagle, candidato de la Concertación de Partidos por la Democracia -de centroizquierda-, ex presidente (1994-2000) y senador por la Región de los Ríos (Circunscripción 16) al momento de la elección; Jorge Arrate Mac Niven, candidato de Juntos Podemos Más, coalición de izquierda formada por el Partido Comunista de Chile (PCCh), el Partido Humanista y la Izquierda Cristiana; y Sebastián Piñera Echenique, candidato de Coalición por el Cambio.

Los principales ejes temáticos sobre los cuales se concentró el debate fueron, por un lado, la delincuencia y el narcotráfico, señalados como los principales problemas que aquejaban a los chilenos y, por el otro, la necesidad de profundizar las políticas públicas orientadas a salud, educación y vivienda. El último bloque del debate introdujo la pregunta 
“Por qué quiere ser Presidente de la República?”, ante la cual Piñera remarcó su férreo posicionamiento como el candidato del cambio, distanciándose tanto de su contrincante Frei -quien, en palabras de Piñera, "tuvo su oportunidad y la dejó pasar"- como de la clase política en general. Señaló que si "tuviese el privilegio" sería el presidente "del cambio y la unidad nacional, que restablezca la cultura de hacer las cosas bien y de forma honesta" (TVN, 2009). Este cambio se cristalizaría en la generación de empleo, el combate a la pobreza, la derrota de la delincuencia y la resolución de los problemas de salud y justicia. El candidato de la Concertación, Frei Ruiz-Tagle, se manifestó como el continuador de las políticas de Michele Bachelet (2006-2010), así como de los ideales de la Concertación, apelando a la necesidad de luchar por "la grandeza de Chile", en base al establecimiento de un gran pacto social. El foco de su posicionamiento se centró en el fortalecimiento del Estado y su rol en la protección de las clases medias y los adultos mayores.

El segundo debate analizado en este corpus se realizó luego de los comicios del 13 de diciembre, que eliminaron de la carrera presidencial a los candidatos Arrate (6,21\%) y EnríquezOminami (20,13\%). A una semana de celebrarse los comicios definitivos, el 11 de enero de 2010 se presentaron en los estudios de la Asociación Nacional de Televisión de Chile (Anatel), los candidatos Eduardo Frei Ruiz-Tagle (29,6\%) y Sebastián Piñera (44,06\%).

En este encuentro, Frei propuso reformas educativas y laborales, con un Estado más presente en estas áreas, triplicar la inversión en cultura y apoyar el pedido de acceso al mar de Bolivia, aunque sin cesión de soberanía. En el caso de Piñera, hizo foco en el combate al narcotráfico, la "mano dura" contra la delincuencia, el impulso a la flexibilización laboral, el mantenimiento del carácter privado del sistema educativo y la no cesión de territorios a Bolivia, sustentada en un discurso nacionalista remozado.

En el último bloque de este debate -"Mensaje final de compromiso con Chile"- el candidato de la Concertación ratificó su voluntad de continuar y profundizar las políticas implementadas por su antecesora, además de reconocer la necesidad de introducir las "correcciones que Chile necesita", en alusión a la pérdida de votos sufrida por la coalición de partidos en la primera vuelta. Piñera, por su parte, señaló que gobernaría para todos los chilenos, "pero con un cariño y un compromiso muy especial con los que más necesitan, la clase media, los más pobres, los que están sin trabajo, las dueñas de casa, los adultos mayores, los que viven con alguna discapacidad" (Anatel, 2010).

En Perú se organizaron seis debates electorales, tres para la primera vuelta y tres para la segunda. El último debate previo a los comicios de abril de 2016 fue organizado el 3 de abril por el Jurado Nacional de Elecciones (JNE), IDEA Internacional y el Consorcio de investigación Económica y Social. En esta oportunidad se presentaron diez de los diecinueve candidatos inscriptos inicialmente: Alfredo Barnechea de Acción Popular; Ántero Flores-Aráoz del Partido Político Orden; Keiko Fujimori de Fuerza Popular; Alan García de Alianza Popular (Apra-PCP); Miguel Hilario de Progresando Perú; Pedro Pablo Kuczynski de Peruanos por el Kambio; Verónika Mendoza del Frente Amplio; Alejandro Toledo de Perú Posible; Fernando Olivera del Frente Esperanza; y Gregorio Santos de Democracia Directa.

Los principales temas que se discutieron fueron corrupción, salud y educación pública, pobreza, empleo, seguridad ciudadana y reforma judicial. En el último bloque del debate -"Mensaje final"-, los candidatos expresaron al electorado los motivos por los que debían 
optar por ellos. En un claro ataque al candidato de Peruanos por el Kambio, Alejandro Toledo hizo hincapié en su origen andino -en alusión al origen alemán y franco-suizo del padre y la madre de Kuczynski respectivamente ${ }^{5}$-, elemento que retomaría PPK en futuras comunicaciones para delimitar adecuadamente su perfil público como un "verdadero peruano". PPK, por su parte, enfatizó en su capacidad de trabajo, sosteniendo que, a pesar de haberlo hecho toda su vida, persistiría en su afán "para que cada peruano tenga salud, educación y seguridad", con un discurso cercano y personalizado. Keiko Fujimori apeló a la reconciliación y se comprometió "al respeto irrestricto del orden democrático y los derechos humanos (...), ser drástica en la lucha contra la corrupción respetando la independencia de poderes" y no utilizar el poder político para favorecer a miembros de su familia. Cerró su alocución con un tajante "Nunca más un 5 de abril", en alusión al autogolpe de Estado perpetrado por su padre.

En los comicios celebrados el 10 de abril, Keiko Fujimori obtuvo el primer lugar con el $39.86 \%$ de los votos, mientras que PPK obtuvo el segundo lugar con el 21,05\%. A partir de entonces, la polarización entre las fuerzas fujimoristas y anti-fujimoristas fue hábilmente explotada por el equipo de PPK, a partir de la redefinición estratégica de su posicionamiento como un defensor de la democracia y el respeto de las libertades políticas. Esta redefinición no estuvo exenta de un uso excesivo del fantasma de la dictadura, que caló hondo en una sociedad atravesada por el recuerdo reciente del conflicto armado interno. Antes de la celebración de los comicios definitivos planificados para el 5 de junio, se realizaron tres debates más, dos entre los candidatos y uno entre los equipos técnicos. Para este artículo se analiza el segundo de estos debates -y último entre los candidatos- , desarrollado el 29 de mayo en la Universidad de Lima. En su Mensaje final, Keiko apeló a la necesidad de construir un Perú reconciliado, más justo, más moderno y más humano, centrando su ataque en el gobierno que culminaba. Por su parte, PPK empleó sus escasos minutos para atacar a su contrincante: "quiero defender la democracia, es lo único que funciona. No más grupos Colina, no más esterilizaciones forzadas (...). Esta libertad está en grave riesgo en el Perú. Hago un llamado a los ciudadanos a cerrar el paso con nuestros votos a la dictadura" (JNE, 2016).

A partir de este análisis podemos establecer algunas conclusiones parciales. Ambos construyeron sus candidaturas como outsiders de la política, posicionándose en el eje del cambio pro futuro, a pesar que ambos tenían trayectoria pública. Esta renovación vendría a restablecer el valor de la honestidad y la cultura del trabajo. Frente a un escenario de segunda vuelta, Piñera continuó fortaleciendo su posicionamiento apelando al agotamiento del proyecto político representado por su contrincante, mientras que PPK reorientó su candidatura capitalizando el miedo al retorno dictatorial.

\section{Del Estado ineficiente al "gobierno de los mejores": análisis de los planes de gobierno}

El Programa para el cambio, el futuro y la esperanza elaborado por el Grupo Tantauco para la candidatura de Sebastián Piñera, fue presentado en octubre de 2009. Tras un 
sucinto diagnóstico de la situación del país en el que se acusaba a la Concertación de haber perdido la fuerza y la voluntad que la caracterizó durante sus primeros ocho años de gobierno, la "Carta abierta a todos los chilenos y chilenas" proponía un cambio y una nueva forma de gobernar.

La abstracta apelación al cambio comenzó a adquirir una forma más concreta: se trataba de la opción entre el pasado y el futuro, donde el pasado era sinónimo de "desempleo, delincuencia, corrupción y estancamiento" y el futuro, de progreso. Llama la atención la referencia al plebiscito de 1988, donde el cambio fue necesario para el retorno democrático y su comparación con la oportunidad histórica que se abría en 2009 para iniciar la senda del progreso (Coalición por el Cambio, 2009, p. 5).

La "nueva forma de gobernar", por su parte, prometía restablecer la cultura de "hacer bien las cosas", para lo cual era necesario un "verdadero renacimiento que nos libere de este estado de letargo que parece invadirnos, y que (...) desate las fuerzas de la libertad, la innovación, la creatividad y el emprendimiento" (p. 5).

El carácter mesiánico de esta declaración de principios se observa, asimismo, en la definición del carácter tecnocrático de su gobierno y la voluntad de asignar los cargos a hombres y mujeres expertos. Esta utilización maniquea de una supuesta rivalidad entre la tecnocracia y la política se observa en la explícita valoración del conocimiento y la experticia adquirida en la esfera privada -que se pone a disposición del bien común-, en detrimento de un ethos político guiado sólo por el interés personal.

A nadie se le pedirá su carné de militante, pero a todos se les exigirá un currículum de excelencia, honestidad y vocación de servicio público. Gobernaremos con los mejores. Con una verdadera selección nacional y la regla será muy simple: el que mete los pies, para su casa; el que mete las manos, a la justicia (Coalición por el Cambio, 2009, p. 7).

Esta fórmula del "gobierno de los mejores" fue utilizada por gran parte de las propuestas de derecha surgidas en los últimos años para anunciar la llegada a la gestión pública de un equipo de expertos ${ }^{6}$. El gobierno de PPK también apeló a esta caracterización, refiriendo a su equipo como "un gabinete de lujo, de la mejor gente de todo el Perú" (Nercesian y Cassaglia, 2019).

La modernización del Estado para tornarlo eficiente implicaría la instauración de un sistema meritocrático de selección de funcionarios, ofreciendo incentivos económicos a quienes se destacasen por sus logros (p. 34) -una suerte de comisión por objetivos-, práctica habitual en el mundo corporativo.

Con frecuencia la idea del mejor equipo iba acompañada por la construcción de una épica en torno a la gestión gubernamental (Varas, 2013), comparable, según Piñera, con el sacrificio de los soldados de las guerras de Independencia y la Guerra del Pacífico (p. 63).

La proclama de la gesta histórica, el discurso del sacrificio, la apuesta a abandonar los privilegios y participar en política para contribuir al progreso del país, son expresión de un nacionalismo remozado que caracterizó buena parte de su discurso de campaña y de su gobierno. El Plan de Gobierno que el equipo de Peruanos Por el Kambio presentó al Jurado Nacional de Elecciones (JNE) en enero de 2016, se centró en cuatro objetivos: seguridad 
ciudadana, entendida en un sentido amplio que abarca desde la lucha contra la delincuencia hasta la consolidación de un régimen de estabilidad jurídica que lograse atraer inversiones; recuperación del dinamismo económico para reducir los niveles de pobreza y desocupación; lucha contra la corrupción; e inversión social para reducir la desigualdad de ingresos.

Al igual que el programa propuesto por el equipo de Piñera, PPK remarcaba la necesidad de cambiar la forma de gobernar. Según su diagnóstico, la herencia recibida, "un Estado ineficiente, que no está atento a las necesidades del país y que utiliza los recursos financieros públicos sin previsión, sin transparencia y a veces en su propio beneficio” (p. 17), favorecía la corrupción, por lo que se exigía una total transformación del sistema jurídico e institucional. Esta nueva forma de gobernar se caracterizaría por "la honestidad, la transparencia, la eficiencia, la más alta función basada en el mérito, la vocación de servicio y la solidaridad con los más necesitados" (p. 16). Las propuestas para materializar estos cambios involucrarían, tal como en la propuesta de Piñera, eficiencia, experticia con un sistema de asignación de cargos basado en la meritocracia-, vocación de servicio público y transparencia en la gestión.

En Chile, Coalición por el Cambio y, particularmente, una facción de la ex Alianza por Chile liderada por partidarios de la UDI y la Fundación Jaime Guzmán, se embarcaron en un proyecto de renovación no sólo del espectro político, sino también de la derecha. Esta nueva derecha sería distinta de la antigua derecha chilena, pero también diferente a la del resto del mundo en un aspecto particular: su vocación por los más pobres, inspirada en valores cristianos (Varas, 2013, p. 109). La utilización de banderas y proclamas propias de los partidos de izquierda tradicionales significó un quiebre respecto al histórico posicionamiento de la derecha, que no estuvo exento de conflictos al interior de la coalición gobernante entre quienes apoyaban una derecha más tradicional y conservadora y quienes postulaban la necesidad de refundarla.

El caso de Perú, en cambio, al no haber experimentado un "giro a la izquierda" -descontando el intento frustrado de la "gran transformación" que intentó encabezar Ollanta Humala entre 2011 y 2016-, no exhibió rasgos de tamaña ruptura. En efecto, si bien en los dos gobiernos se observa una propuesta de cambio de forma -de hacer política-, antes que de fondo - puesto que ninguno cuestionó el modelo de desarrollo primario-exportador y los imperativos neoliberales-, en Perú se trató, en general, de un proceso de continuidad. El quiebre se produjo, como vimos anteriormente, a partir de la segunda vuelta, cuando el equipo de PPK perfiló su posicionamiento como el adalid de la democracia.

\section{La construcción del liderazgo político y la proclamación de una gesta histórica en los spots de campaña}

Los spots de campaña constituyen una de las principales herramientas de publicidad política. En primer lugar, porque a través de ellos, los partidos y candidatos logran cristalizar audiovisualmente su identidad política, los ejes que consideran prioritarios y los valores con los cuales pretenden ser asociados públicamente. Como sostienen García 
Beadoux y D' Adamo (2006), los spots permiten tener el control total del mensaje emitido, a diferencia de los debates y otras formas de comunicación con el electorado. Pero, además, su difusión y repetición a través de los medios masivos, les ofrece una capacidad de alcance mayor, especialmente hacia aquellos ciudadanos que se informan exclusivamente por el medio televisivo y no tienen vínculos con los partidos.

El spot "Súmate al cambio" que se convertiría en el lema de la campaña de Piñera se elaboró a partir de una adaptación de la canción de Los Náufragos, una banda argentina cuya popularidad se debe, en parte, al tema utilizado en esta instancia "Quiero gritar que te quiero" de 1971. La letra original, modificada para su adecuación a la campaña expresaba en tono de celebración y alegría:

Quiero gritar ¡Viva el cambio! / que Chile entero / se sume cantando / porque la esperanza / de un nuevo futuro / está por nacer / ¡Nacer! ¡Nacer! ¡Nacer! / Quiero verte soñando / lleno de colores / que hablan de cambio. / Los mismos de siempre / se van a sus casas / ¡No los vemos más! / ¡No más! ¡No más! ¡No más! / Hey súmate, ven a cantar / aquí está tu lugar / que Chile / ¡contigo va a cambiar! / ¡Cambiar! ¡Cambiar! ¡Cambiar! / Porque digan lo que digan / ¡Queremos el cambio! / una nueva vida / gritando al futuro / cambiemos la historia / ¡Chilenos con voz! / ¡Con voz! ¡Con voz! ¡Con voz! / ¡La la la la la la! Piñera con todos / ¡La la la la la la! ¡Súmate al cambio! / ¡Súmate! (Coalición por el Cambio, 2009)

El video, difundido en diciembre de 2009, cuando la contienda se definiría entre Piñera y Frei Ruiz-Tagle, intercalaba imágenes de personas de distintas generaciones abrazándose y besándose, en un ámbito festivo, de liberación y esperanza, en el que Piñera aparecía como cabecilla de un proyecto colectivo. Podemos asumir que Piñera capitalizó su escaso nivel de notoriedad pública para ubicarse en el eje del cambio, con pocas apelaciones a temas prioritarios y una mayor apelación a las emociones (García Beadoux y D’ Adamo, 2006). En efecto, en el video aparece luego de la frase "los mismos de siempre se van a sus casas, no los vemos más”, marcando un distanciamiento con las formas previas de gobierno y en una actitud de team leader.

La utilización de un spot positivo como cierre de su campaña, con un sutil ataque a "los mismos de siempre" pero no direccionado a ninguno de sus contrincantes, le sirvió para fortalecer una imagen de conciliación y de superación de la conflictividad social, desde una estrategia de carácter mítico que lo construyó como un personaje heroico (JohnsonCartee y Copeland, 1997). La figura del héroe se cristaliza en las imágenes del candidato Piñera rodeado de multitudes que lo aplauden y lo abrazan (Roberts, 1993). Estas escenas se repitieron en buena parte de sus spots posteriores, donde el candidato aparecía atendiendo a las necesidades de diversos grupos de personas en distintas geografías del país. El mensaje difundido por PPK en sus spots también se centró en la oportunidad histórica que representaban las elecciones de 2016 para decidir el futuro del país. Su lema de campaña "Un nuevo Perú", proponía el establecimiento de un pacto "con la gente" para cambiar la forma de gobernar, atravesada por relaciones de amiguismo e interés personal". En este caso, como en el de Piñera, no se atacaba directamente a los contrincantes, pero 
se aludía a una forma de gobernar afincada en la clase política que ha naturalizado prácticas corruptas.

El compromiso constituyó la base del pacto de PPK con la ciudadanía: Perú necesitaba más esfuerzos para su refundación. La construcción de Kuczynski como líder colectivo se logró a partir de relatos en primera persona que resaltaban dicho compromiso con el cambio, así como de testimonios de diversas personas que exaltaban su honestidad, su sacrificio y su vocación de servicio.

El spot "Bienvenido al Kambio", difundido en 2015 para afianzar el grado de notoriedad del candidato entre el electorado, combinaba relatos de un locutor con intervenciones de ciudadanos y ciudadanas -con sus respectivos nombres y apellidos- de distintos lugares de Perú.

[Locutor] Este hombre hizo su propio camino. Nació en Lima, creció en Iquitos, Puno y Cusco. Se formó con becas y con su propio esfuerzo. Creció en la vida sin dejar nunca de ser honesto. [Ciudadano 1. Huaycán] Es un hombre que ha venido desde abajo, su familia ha venido al Perú y ha invertido para ayudar a que los peruanos mejoren. [Locutor] Un hombre que dialoga, escucha y que hace de la solidaridad un medio para entender a todos (...). Un peruano que tiene la honestidad, la experiencia y un gran sueño: cambiar el Perú (...) $[\mathrm{PPK}]$ Estamos en una encrucijada: o seguimos como antes o tomamos un nuevo camino. Yo creo que los peruanos podemos vivir mucho mejor. Si tú también crees en eso, bienvenido al kambio (PPK, 2015).

La retórica de la experticia se construyó en posteriores anuncios, como la canción "Él sí sabe" que difundió el equipo de campaña en mayo de 2016. Así como en la estrategia desarrollada por Piñera, la decisión de difundir spots positivos, enfocados en los atributos del candidato, se orientó a neutralizar los ataques de sus contrincantes -no ser un "verdadero peruano" y, en consecuencia, no defender los intereses nacionales- $y$, vía defensa de la democracia, a canalizar el voto anti-fujimorista.

\section{¿Una nueva forma de hacer política?}

El análisis combinado de los spots televisivos, la participación en debates y los programas de gobierno, ofrece algunas claves explicativas para comprender cómo se construyó comunicacionalmente el pasaje de empresarios a presidentes de dos exponentes del ámbito corporativo. Y, en el caso de Piñera, el inicio de su consolidación como líder político que no sólo logró culminar su primer mandato con un nivel de aprobación del 50\% (Mascareño y Medina, 2014), sino que además fue nuevamente electo presidente en 2017.

La idea de renovación como pilar de su construcción discursiva se consolidó en un contexto de desgaste de la coalición partidaria dominante en el caso de Chile, y en un escenario de temor al retorno dictatorial en Perú. Los representantes del activismo empresarial democrático (Durand, 2010) hallaron en la retórica del cambio la vía para diferenciarse 
tanto de sus rivales de signo contrario, como de quienes pertenecían al propio espectro de la derecha. Una derecha que, aggiornada a los nuevos tiempos, debía ser democrática y presentarse a la ciudadanía como la única opción viable para superar la crisis social y política desatada por décadas de un empleo ineficiente de las capacidades del Estado. Como se expuso a lo largo del escrito, cuatro fueron los mecanismos utilizados para canalizar el discurso del cambio. El primero fue la ponderación de su capacidad de gestión, avalada por sus años al frente de organismos internacionales y ocupando las dirigencias de holdings multinacionales. El segundo, la consolidación de un diagnóstico de urgencia respecto de la situación del país que exigía su intervención. El tercer mecanismo fue la construcción de este involucramiento como una épica, un sacrificio personal -en términos simbólicos y económicos, factor que no dejó de remarcarse en las comunicaciones mediáticas afines a sus candidaturas- en pos del progreso colectivo. Y, en último lugar, la eficiencia como el precepto por el cual ellos, provistos de saberes expertos y nutridos de una lógica tecnocrática que valora la designación de cargos en función del mérito individual, debían ponerse al mando.

El éxito de esta estrategia, acompañada de un tono refundacional, inauguró un período signado por la canalización de la idea de renovación como un medio para lograr la aceptación pública de representantes del empresariado. "Meterse en política" (Vommaro, 2014), significó, en buena medida, llegar para quedarse. Una forma de participación en la política que garantizase la continuidad de un modelo socioeconómico cuya hegemonía estaba siendo erosionada desde principios de siglo por los llamados gobiernos posneoliberales de la región (Ansaldi, 2017; Giordano, 2014; Nercesian, 2017).

El desenlace de sus gobiernos distó, en parte, de la retórica triunfalista que pregonaban en sus campañas. Por un lado, Piñera debió cambiar casi en su totalidad el gabinete inicial conformado por ministros empresarios antes de la culminación de su primer año, mientras que Kuczynski fue procesado por delitos de corrupción vinculados con la constructora Odebrecht, y antes de ser sometido a juicio político por parte del Congreso, el 21 de marzo de 2018 presentó su renuncia.

\section{Notas}

1. El 5 de abril de 1992, el presidente ordenó el cierre del Congreso, la suspensión de las actividades del Poder Judicial y el despliegue de las Fuerzas Armadas en distintas regiones del país. Los posteriores ocho años de gobierno estuvieron signados por las limitaciones a la libertad de prensa, la persecución a la oposición y la corrupción. En 1995 modificó la Constitución Nacional para presentarse a la reelección.

2. En un marco de incremento de la crisis política y social desatada por la difusión de videos que mostraban el pago de coimas a funcionarios a través del Jefe del Servicio de Inteligencia Nacional Vladimiro Montesinos, la creciente oposición a la tercera candidatura de Fujimori y la ruptura de las alianzas al interior de la coalición de gobierno.

3. Los primeros debates presidenciales de la región se desarrollaron en la década de 1960 en Brasil y Venezuela, pero no fue hasta la década de 1990 con la recuperación democrá- 
tica que se retomó esta tradición. En Chile, el primer debate presidencial se desarrolló en 1989 entre Patricio Aylwin y Hernán Büchi en el marco de la primera elección democrática celebrada tras el fin de la dictadura pinochetista. En el caso de Perú, el primer debate se desarrolló en 1990 entre Mario Vargas Llosa y Alberto Fujimori.

4. La elección de estas dos instancias, en detrimento de los otros debates realizados para la primera y segunda vuelta electoral, responde, para el primer caso, a la intención de reconstruir los posicionamientos estratégicos iniciales que delinearon la imagen de los candidatos y, para el segundo caso, al propósito de rastrear cambios y continuidades en la estrategia de comunicación original.

5. En su alocución expresó su temor a que Perú fuera administrado por "personas que fingen ser peruanos" (RPP Noticias, 2016).

6. El gobierno argentino de Mauricio Macri calificó a su gabinete como "el mejor equipo de los últimos 50 años", mientras que el ex mandatario brasilero Michel Temer refirió a su gestión como un "gobierno de notables" (Nercesian y Cassaglia, 2019).

7. "No se trata sólo de cambiar el gobierno. Se trata de cambiar la forma de gobernar, con un gobierno limpio, formado por los mejores profesionales, no por los compinches y los patas" (PPK, febrero de 2016).

\section{Bibliografía}

Ansaldi, W. (2017). Arregladitas como para ir de boda. Nuevo ropaje para las viejas derechas. Revista Theomai 35.

Aparece spot de PPK que promete un "nuevo Perú". (1/05/2016). LaMula.pe [YouTube] Recuperado el 6/01/2020 de: https://www.youtube.com/watch?v=Kh_Njvj7cFI

Castells, M. (2012[2009]). Comunicación y poder. Madrid: Alianza Editorial.

Berger, P. y Luckman, T. (1986[1966]). La construcción social de la realidad. Buenos Aires: Amorrortu.

Chihu, A. (2010a). El framing del spot político. México DC: Miguel Ángel Porrúa/UAMIztapalapa.

Durand, F. (2010). Empresarios a la Presidencia. Revista Nueva Sociedad 225. Disponible en: https://nuso.org/articulo/empresarios-a-la-presidencia/

Fazio Rigazzi, H. (2011). Un país gobernado por uno de sus dueños. Santiago: LOM.

García-Beaudoux, V. y D’Adamo, O. (2006). Comunicación política y campañas electorales. Análisis de una herramienta comunicacional: el spot televisivo. Polis: investigación y análisis sociopolítico y psicosocial 2, pp. 81-111.

Garretón, M. y Garretón, R. (2010). La democracia incompleta en Chile: la realidad tras los rankings internacionales. Revista de Ciencia Política de la Pontificia Universidad Católica de Chile 30 (1), pp. 115-148. Disponible en: Disponible en: http://www.redalyc. org/articulo.oa?id=32414670007

Giddens, A. (2011[1984]). La constitución de la sociedad. Bases para la teoría de la estructuración. Madrid: Amorrortu. 
Giordano, V. (2014). ¿Qué hay de nuevo en las "nuevas derechas"? Revista Nueva Sociedad 254. Disponible en: https://nuso.org/articulo/que-hay-de-nuevo-en-las-nuevas-derechas/

Goffman, E. (2006[1974]). Frame analysis: los marcos de la experiencia. Madrid: Centro de Investigaciones Sociológicas.

Landi, O. (1991). Videopolítica y cultura. Revista Diálogos de la comunicación 29. Disponible en: http://dialogosfelafacs.net/wp-content/uploads/2015/74/74-revista-dialogosvideopolitica-y-cultura.pdf

Mascareño, C. y Medina, M. B. (03/03/2014). Piñera culmina gobierno con un $50 \%$ de aprobación y $36 \%$ de rechazo según la encuesta Adimark de febrero. La Tercera. Disponible en: https://www.latercera.com/noticia/pinera-culmina-gobierno-con-un-50-deaprobacion-y-36-de-rechazo-segun-la-encuesta-adimark-de-febrero/

McCombs, M. y Evatt, D. (1995). Los temas y los aspectos: explorando una nueva dimensión de la agenda setting. Comunicación y Sociedad 8, pp. 7-32.

McCombs, M. y Shaw, D. (1972). The agenda setting function of the media, Public Opinion Quarterly 36, pp. 176-187.

Nercesian, I. (2016). Perú 2016: una disputa entre las derechas. Revista Política Latinoamericana 2. Disponible en: http://www.politicalatinoamericana.org/revista/index.php/ RPL/article/view/28/100

Nercesian, I. (2017). Debates en torno a los gobiernos posneoliberales: un estado de la cuestión. Revista Pilquen 20 (3). Disponible en: http://revele.uncoma.edu.ar/htdoc/ revele/index.php/Sociales/article/view/1710/1735

Obscura Gutiérrez, S. (2009). Identidad e imagen en los spots de la campaña presidencial mexicana del 2006. Cultura y representaciones sociales 6, pp. 73-99. Disponible en: http:// www.scielo.org.mx/pdf/crs/v3n6/v3n6a4.pdf

PPK (2015). Bienvenido al Kambio. [YouTube]. Recuperado el 6/01/2020 de: https://www. youtube.com/watch? $\mathrm{v}=\mathrm{dHHeBQX}-1 \mathrm{X} 8 \& \mathrm{t}=6 \mathrm{~s}$

PPK SPOT: "Las elecciones más importantes de nuestra historia" - Campaña 2016. (17/02/2016). [YouTube] Recuperado el 6/01/2020 de: https://www.youtube.com/ watch? $=$ ofMA3-tW3Yc

Quevedo-Redondo, R. y Portalés-Oliva, M. (2017). Imagen y comunicación política en Instagram. Celebrificación de los candidatos a la presidencia del Gobierno. El profesional de la información 26 (5).

Spot - Sebastián Piñera “SSúmate al Cambio!” (2009). [YouTube]. Disponible en: https:// www.youtube.com/watch?v=6xZZqWq6Gh0

Tanaka, M. (2002). De la crisis al colapso de los sistemas de partidos y los retos de su reconstrucción: los casos de Perú y Venezuela. Lima: IEP.

Tanaka, M. (2006). Los sistemas de partidos en los países andinos, 1980-2005: reformismo institucional, autoritarismos competitivos y los desafíos actuales. Working paper \#324, Kellog Institute. Disponible en: https://kellogg.nd.edu/sites/default/files/old_files/documents/324.pdf

Varas, A. (2013). El gobierno de Piñera (2010-2014). Santiago: Catalonia.

Vommaro, G. (2014). «Meterse en política»: la construcción de PRO y la renovación de la centroderecha argentina. Revista Nueva Sociedad 254. 


\begin{abstract}
The increasing insertion of businessmen in the highest governmental spheres of Latin American countries has aroused a renewed interest in analyzing and understanding the modalities of building political leaderships, their tools and strategies.

This article proposes a comparative analysis of the political image building process of two exponents of the private-business sphere, the former Peruvian president Pedro Pablo Kuczynski (2016-2018) and the current Chilean president, Sebastián Piñera (2010-2014 / 2018-). It is intended to systematize this process, highlighting the combination of tools and tactics of communication, image and political marketing used to position them in the public sphere as representatives of a "new policy".
\end{abstract}

Keywords: political image - leadership - businessmen - new right - change - Peru - Chile.

Resumo: A crescente inserção de empresários nas mais altas esferas governamentais dos países latino-americanos despertou um interesse renovado em analisar e entender as modalidades de construção de lideranças políticas, suas ferramentas e estratégias.

Este artigo propõe uma análise comparativa do processo de construção da imagem política de dois expoentes da esfera empresarial privada, o ex-presidente peruano Pedro Pablo Kuczynski (2016-2018) e o atual presidente chileno, Sebastián Piñera (2010-2014 / 2018-). Pretende-se sistematizar esse processo, destacando a combinação de ferramentas e táticas de comunicação, imagem e marketing político usadas para posicioná-los na esfera pública como representantes de uma "nova política".

Palavras-chave: imagem política - liderança - empresários - nova direita - mudança Peru - Chile.

[Las traducciones de los abstracts fueron supervisadas por el autor de cada artículo] 